\title{
A NEW HEXASTYLIS (ARISTOLOCHIACEAE) FROM NORTHEAST ALABAMA (U.S.A.) WITH NOTES ON THE SPECIES "GROUPS" WITHIN THE GENUS
}

\author{
Brian R. Keener \\ University of West Alabama \\ Biological and Environmental Sciences \\ Livingston, Alabama 35470, U.S.A. \\ bkeener@uwa.edu \\ ABSTRACT
}

A new species of Hexastylis-H. finzelii-is herein described from northeast Alabama. The historical species groups within Hexastylis are re-evaluated.

RESUMEN

Se describe una especie nueva de Hexastylis- H. finzelii-del nordeste de Alabama. Se reevaluan los grupos de especies históricos de Hexastylis.

INTRODUCTION

Hexastylis Raf. (Aristolochiaceae) is a genus of primitive flowering plants comprised of evergreen, terrestrial, acaulescent herbs endemic to the southeastern United States. The recognition of Hexastylis at the genus level has been controversial, as numerous authors have opted for its inclusion (along with other Asian allied genera) into a broader circumscribed Asarum L. (Kelly 1997, 1998, 2001; Sinn 2015, 2017; Sinn et al. 2015; Takahashi \& Setoguchi 2018), while others have maintained Hexastylis as distinct from the Asian-North American Asarum sensu stricto (Blomquist 1957; Gaddy 1987; Whittemore \& Gaddy 1997; Weakley 2015).

Until recently, Hexastylis was thought to be comprised of 15 specific and infraspecific taxa. Discoveries in the last five years have led to the description of two new species from the southeastern United States but assigned to the genus Asarum, A. chueyi B.T. Sinn (Sinn 2015) and A. rosei B.T. Sinn (Sinn 2017). However, both of these taxa align with the description of Hexastylis and will soon be transferred to that genus (Weakley pers. comm.). The description of this new species from NE Alabama will bring the total number of Hexastylis entities to 18 including the two to be transferred from Asarum.

\section{TAXONOMIC TREATMENT}

Hexastylis finzelii B.R. Keener, sp. nov. (Fig. 1). Type: United STATES. Alabama: Marshall Co.: 6.75 air mi NW of Guntersville, along N side of Tennessee River near the SE corner of Bishop Mountain, W of Hambrick Hollow, $34.42600^{\circ} \mathrm{N}$ -86.38011W, 11 Apr 2019, B.R. Keener 11,076 with Brian Finzel (HоLотYPE: UWAL; IsotyPEs: AMAL, APSC, AUA, BRIT, MO, NCU, TROY, UNA, US).

Similar to H. speciosa and H. arifolia. Differs from H. speciosa by the calyx lobes erect (vs. recurved), lower calyx tube below outward flare distinctly shorter than upper tube (vs. lower calyx tube as long as or longer than upper tube), and style appendages maroon (vs. greenish). Differs from H. arifolia by calyx shape open cup-shaped (vs. urceolate).

Terrestrial acaulescent herbs from short rhizomes. Leaves: petioles to $23 \mathrm{~cm}$ long; blades hastate-sagittate with rounded basal lobes to sometimes triangular to less commonly almost cordate; largest leaves 8-12(15) cm long by 8-10(12) cm wide. Flowers: peduncle 2-5 cm long; Calyx 25-30 mm long, 16-19 mm wide, rounded at base; tube in two parts divided by abrupt out-flaring, with the lower tube campanulate and shorter than upper tube, 4-7 mm long; upper tube more or less cup-shaped or short cylindrical, 10-11 mm long; lobes three, erect, broadly triangular, wider than long, 8-12 mm long, 15-16 mm wide. Stamens 12, filament with connective to $3.2 \mathrm{~mm}$ long, theca extrorse, $2.5-2.9 \mathrm{~mm}$ long, connective only slightly prolonged passed theca.

J. Bot. Res. Inst. Texas 14(2): $161-166.2020$

https://doi.org/10.17348/jbrit.v14.i2.999

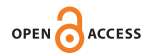



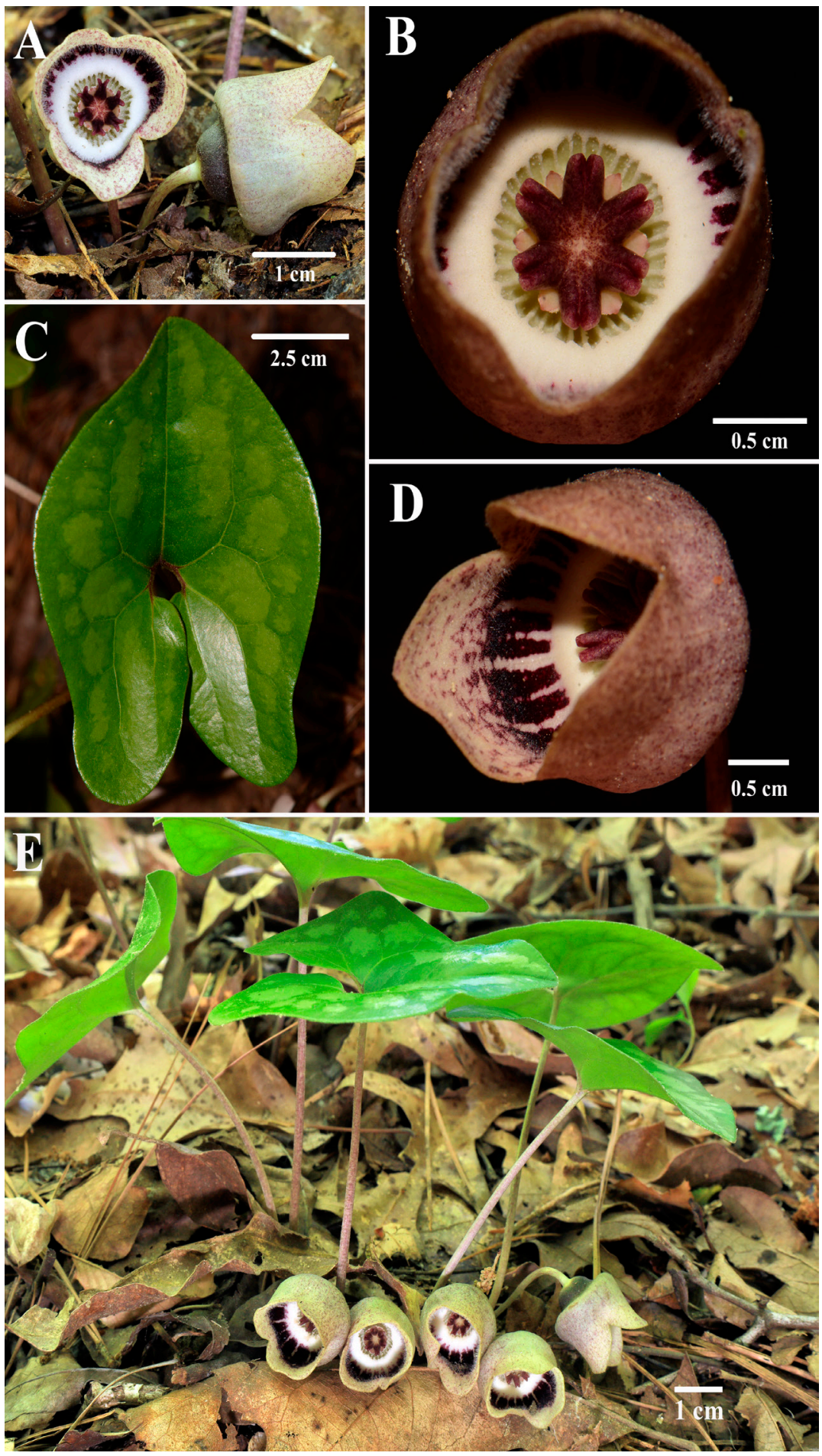

FIG. 1. Hexastylis finzelii B.R. Keener. A. Flowers front and side. B. Flower close-up view, showing maroon style and style appendages. C. Leaf. D. Flower oblique view. E. Habit. (Photos A and E by Alan Cressler; Photos B, C, and D, by Brian Finzel). 
Styles maroon, with extensions bifid to stigma, 1.8-2.0 mm long; stigma widely elliptic $1.2 \mathrm{~mm}$ long, $0.8 \mathrm{~mm}$ wide.

Additional specimens examined: U.S.A. Alabama: Marshall Co.: 6.75 air mi NW of Guntersville, along N side of Tennessee River near the SE corner of Bishop Mountain, W of Hambrick Hollow, $34.42600^{\circ} \mathrm{N}-86.38011^{\circ} \mathrm{W}, 6$ Apr 2019, B. Finzel s.n. (UWAL); near $34.4262410^{\circ} \mathrm{N}$ $-86.38031^{\circ} \mathrm{W}, 10$ Apr 2019, T.W. Barger with B. Finzel \#SP4302A \& \#SP4302B (ALNHS); [exact location withheld for conservation purposes], 16 May 2020, B.R. Keener et al. 11,803 (UWAL; duplicates to be distributed).

Distribution and habitat.-To date, Hexastylis finzelii is known only from two populations, both from Bishop Mountain in Marshall Co., Alabama. The first of these was discovered in 2019 and serves as the type locality cited above. Upon discovery and initial examination, it was comprised of approximately 125-150 individual plants. The second and much larger population comprised of approximately $1000+$ individuals was discovered in 2020 and is about $2 \mathrm{~km}$ from the type locality. Both populations occur in the Plateau Escarpment of the Southwestern Appalachians ecoregions seemingly at the boundary of the Pennington Formation and Bangor Limestone geologic units with occasional Pottsville Sandstone debris from above (Griffith et al. 2001; Osborne \& Ward 2010). The habitat for both populations is slightly mesic with rocky well-drained soil covered by a regenerated forest several decades old. The forest is mostly of hardwoods, oaks, hickories, sweet gum, and tulip poplar while occasionally cedar and pines are also present. The associated plants do not exhibit any substrate chemistry trend toward acidic or alkaline species likely attributable to the geologic mosaic mentioned above.

Etymology and Common Name.-The epithet honors Mr. Brian Finzel (1971-), a native plant enthusiast, nature photographer, high school science teacher, colleague, and friend. His discovery of the first population of the new entity and dedication to systematic plant photography of the southeastern U.S. flora deserve commemoration. I propose a literal translation combined with laymen's traditional vernacular of related species be employed for the common name, "Finzel's Wild Ginger."

Conservation and IUCN Red List Category.-Hexastylis finzelii should be considered ENDANGERED based on the criteria set forth by the IUCN Red List Criteria (2012).

KEY TO SPECIES OF THE ARIFOLIA-SPECIOSA GROUP

1. Calyx urceolate (Fig. 2), without an abrupt outward flare dividing the calyx tube into distinct lower and upper portions

1. Calyx campanulate-cylindric or cup-shaped with an abrupt outward flare dividing the tube into distinct lower and upper portions.

2. Calyx lobes recurved; lower calyx tube (below outward flare) as long as or longer than upper calyx tube; style appendages greenish

2. Calyx lobes erect; lower calyx tube distinctly shorter than upper calyx tube; style appendages maroon

H. arifolia

H. speciosa

H. finzelii

\section{DISCUSSION}

Hexastylis finzelii is the second Hexastylis endemic to Alabama, a state well documented for high levels of biodiversity. The other endemic, H. speciosa, named for its showy flowers, is only known to occur in three counties in central Alabama (Harper 1924; Keener et al. 2020). Hexastylis speciosa is currently under review by the U.S. Fish and Wildlife to be listed as a Threatened or Endangered species (USFW, ECOS 2020). Ironically, H. finzelii is in much greater need of conservation efforts as the extremely narrow distribution makes it considerably more vulnerable than $H$. speciosa.

\section{SPECIES GROUPS WITHIN HEXASTYLIS}

In the first modern monograph of the Hexastylis, Blomquist (1957) recognized nine species and two additional infraspecific taxa of H. arifolia (Michx.) Small. He also erected three different species "groups" ("Arifolia," "Speciosa," and "Virginica") each named after a taxon included within each group. The Arifolia and Speciosa groups were comprised of a single species each, but with two additional infraspecific taxa within the Arifolia group, leaving the remaining seven species in what he defined as the Virginica group. While Blomquist placed H. arifolia [with infraspecific taxa] and H. speciosa R.M. Harper in different "groups" based primarily on calyx morphology, he recognized the similarities between the two entities as reflected in his key. He separated the 


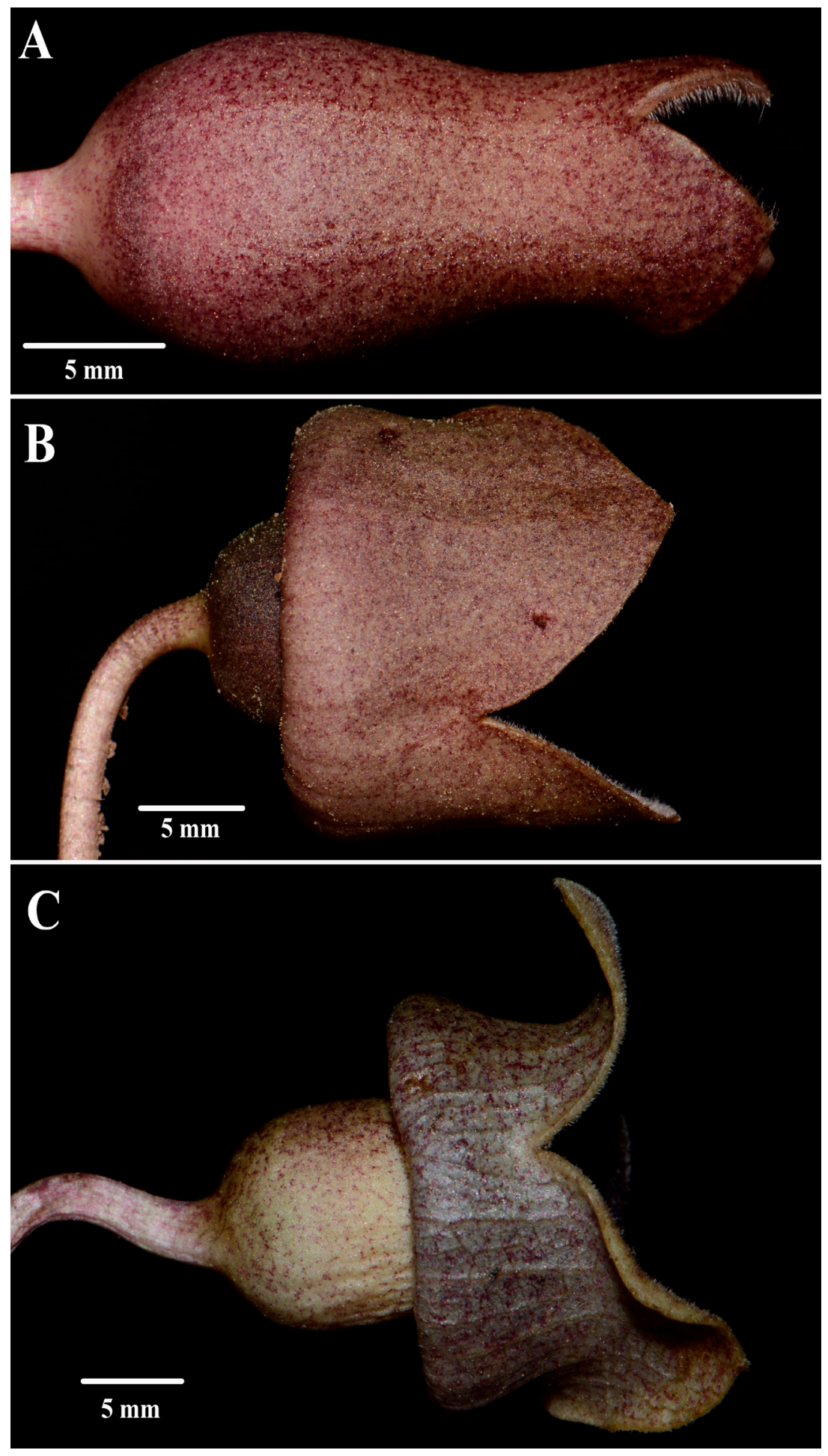

FIG. 2. Comparison of calyx from side view. A. Hexstylis arifolia. B. H. finzelii. C. H. speciosa. (Photos by Brian Finzel). 
Arifolia and Speciosa groups from the Virginica group based on leaf variegation with lighter green between the primary veins and style extensions bifid to the stigmas. These characters create a decisive dichotomy with the Virginica group taxa, which have lighter variegations along the primary veins of the leaves and style extensions only notched at the apex.

Thirty years later, Gaddy (1987) published a revised treatment of Hexastylis including the two new taxa that were described since Blomquist's monograph (1957), both members of the Virginica group. Gaddy maintained the Blomquist species groups while dividing the Virginica group into three subgroups. A broader cladistic analysis by Kelly (1997) included allied genera but had limited Hexastylis sampling and thus did not address species groups within Hexastylis. However, a year later using morphology and the molecular ITS marker, Kelly (1998) demonstrated Blomquist's Arifolia and Speciosa groups to be monophyletic together and basal to a limited sampling but monophyletic Virginica group which was in turn basal to the Asian genus Heterotropa C. Morren \& Decn.

Sinn et al. (2015), using data from the ITS nuclear regions and seven plastid markers, addressed the broader question of generic delineation among Asarum and related genera including Hexastylis. In their study, several more Hexastylis (treated as a section) taxa (15) were utilized in sampling than the earlier Kelly (1998) study. Sinn et al. found similar results to Kelly in that Blomquist's Arifolia and Speciosa groups were monophyletic together and sister to a monophyletic Virginica group that demonstrated three subgroups. One surprising result from the Sinn et al. study was the inclusion of H. lewisii (Fernald) H.L. Blomq. \& Oosting within the arifolia-speciosa clade. It was unexpected because H. lewisii produces lighter green variegations on the primary leaf veins and merely notched style appendages, hallmarks of Blomquist's Virginica group. Using the ITS and matK molecular markers, Takahashi and Setoguchi (2018) reinforced the monophyly of the arifolia-speciosa clade as distinct from other Hexastylis "Virginca group" taxa, but they did not include H. lewisii. However, in recent unpublished data using ITS with indels coded, H. lewisii was found to be in the expected location, within the Virginica group while also maintaining a monophyletic arifolia-speciosa clade (A. Floden pers. comm.).

According to the "group" structure established by Blomquist (1957), Hexastylis finzelii is only the second member of the Speciosa group. This placement is due to the wide calyx opening and outward flare of the calyx tube along with lighter green variegations between the primary veins of the leaves and bifid style appendages. This is notable as all new Hexastylis taxa described since Blomquist's monograph can be attributed to his Virginica group. However, it may be that Blomquist's Speciosa and Arifolia group distinctions are no longer warranted based on the molecular data alluded to earlier. The discovery of $H$. finzelii will facilitate the legitimacy of these groups through future molecular testing with the addition of a new close relative. At this time, the vegetative morphology does not support the group distinctions as the leaves of $H$. finzelii, $H$. arifolia, and $H$. speciosa are essentially indistinguishable from each other though occasionally $H$. speciosa may sometimes seem wider in a few individual leaves. Despite the dramatically different calyx morphology, both $H$. finzelii and H. arifolia have maroon styles and style appendages compared with light green in H. speciosa. Also, given the disjunction of approximately $170 \mathrm{~km}$ between $H$. finzelii and $H$. speciosa coupled with the short-range dispersal mechanisms of Hexastylis, it could be that $H$. finzelii will be found more closely related to the wide-ranging and sympatric H. arifolia than the expected narrow endemic H. speciosa. Going forward, it may be more appropriate to simply recognize two primary groups of taxa in the genus Hexastylis: Arifolia-Speciosa Group [H. arifolia (and varieties), H. speciosa, and H. finzelii] and Virginica Group [all remaining taxa]. Alternatively, based on the molecular data cited above, it may be warranted to transfer the Virginica group taxa to a newly erected genus to achieve a monophyletic classification for each of the two groups. In either scenario, more molecular data is required.

\section{ACKNOWLEDGMENTS}

I appreciate Alan Cressler for making his photo collection available for study and use for publication. I am grateful to John Clark for his help with the figure plates. I thank Noah Yawn and Alan Cressler for sharing the 
location of the second population they discovered in 2020 and Noah for accompanying me in the field. I am grateful for extremely helpful reviewer comments from Larry Davenport and Curtis Hansen which improved the manuscript. Thank you to Aaron Floden, Alan Weakley, and Derick Poindexter for general Hexastylis discussion during the manuscript preparation. I thank Wayne Barger, curator of ALNHS Herbarium for a specimen loan. I am thankful for the research support provided by the Alabama Black Belt Foundation. And most of all, I appreciate Brian Finzel for his confidence that I could tell the world of his discovery.

\section{REFERENCES}

BLomQuist, H.L. 1957. A revision of Hexastylis of North America. Brittonia 8:255-281.

GADDY, L.L. 1987. A review of the taxonomy and biogeography of Hexastylis (Aristolochiaceae). Castanea 52:186-196.

Griffith, G.E., J.M. Omernik, J.A. Сomstock, G. Martin, A. Goddard, \& V.J. Hulcher. 2001. Ecoregions of Alabama. U.S. Environmental Protection Agency, National Health and Environmental Effects Research Laboratory, Corvallis, Oregon, U.S.A.

IUCN. 2012. IUCN Red List and Categories and Criteria, Version 3.1. Prepared by the IUCN Species Survival Commission. Gland Switzerland and Cambridge, UK. International Union for Conservation of Nature and Natural Resources.

Keener, B.R., A.R. Diamond, JR., L.J. Davenport, P.G. Davison, S.L. Ginzbarg, C.J. Hansen, C.S. Major, D.D. Spaulding, J.K. Triplett, \& M. Woods. 2020. Alabama Plant Atlas. url: http://www.floraofalabama.org. Accessed July 2020.

KeLLY, L.M. 1997. A cladistic analysis of Asarum (Aristolochiaceae) and implications for the evolution of Herkogamy. Amer. J. Bot. 84:1752-1765.

KeLLY, L.M. 1998. Phylogenetic relationships in Asarum (Aristolochiaceae) based on morphology and ITS sequences. Amer. J. Bot. 85:1454-1467.

KELLY, L.M. 2001. Taxonomy of Asarum section Asarum (Aristolochiaceae). Syst. Bot. 26:17-53.

Osborne, W.E. \& W.E. WARD II. 2010. Geologic Map of the Guntersville Dam 7.5-minute Quadrangle, Madison and Marshall counties, Alabama. Geological Survey of Alabama, Quadrangle Series Map 53. Tuscaloosa, Alabama, U.S.A.

SINN, B.T. 2015. Asarum chueyi (Aristolochiaceae), a new species from the foothills of the Blue Ridge Mountains of Tennessee and Virginia, USA. Phytotaxa 224(1):85-95.

SINN, B.T. 2017. Asarum rosei (Aristolochiaceae), a new species from the Blue Ridge Escarpment of North Carolina, USA. Phytotaxa 296 (1):53-62.

Sinn, B.T., L.M. Kelly, \& J.V. Freudenstein. 2015. Phylogenetic relationships in Asarum: effect of data partitioning and a revised classification. Amer. J. Bot. 102:765-779.

TAKAHASH, D. \& H. Setoguchi. 2018. Molecular phylogeny and taxonomic implications of Asarum (Aristolochiaceae) based on ITS and matK sequences. PI. Sp. Biol. 33:28-41.

U.S. Fish and Wildife Service/Environmental Conservation Online System. Harper's heartleaf (Hexastylis speciosa). Retrieved July 3, 2020, from https://ecos.fws.gov/ecp0/profile/speciesProfile;jsessionid=4475860E91273C6169C5D31A32CDDBAE ?spcode $=$ Q0ZD

WEAKLEY, A.S. 2015. Flora of the southern and mid-Atlantic states, working draft of 21 May 2015. University of North Carolina Herbarium, North Carolina Botanical Garden, Chapel Hill, NC. Also accessible at http://www.herbarium.unc. edu/flora.htm.

WhITTEMORE, A.T. \& L.L. GAdDY. 1997. Hexastylis. In: Flora of North America Editorial Committee, Flora of North America north of Mexico. Volume 3, Magnoliophyta: Magnoliidae and Hamamelidae. Oxford Univ. Press, New York, New York, U.S.A.Pp. 54-58. 